\title{
Self-esteem, anxiety and coping strategies to manage stress in ice hockey
}

\author{
Adriana Kaplánová* \\ Faculty of Physical Education and Sport, Comenius University in Bratislava, Bratislava, Slovak Republic
}

Copyright: (C) 2018 A. Kaplánová. This is an open access article licensed under the Creative Commons Attribution License (https://creativecommons.org/licenses/by/4.0/).

\begin{abstract}
Background: Sweating, increased heart rate, fidgeting, worrying thoughts and fear of failure are typical symptoms of an inability to manage stress in an important moment of match. Thus, there is well-founded need for psychological training that can help ice hockey players to control their emotions in stressful situations. Objective: Because of a lack of research monitoring mental skills of ice hockey players, the aim of the study is to investigate the relationship between self-esteem, anxiety of ice hockey players and their coping strategies to manage stress. Methods: The study sample consisted of 40 male ice hockey players with age of $21.67 \pm 1.94$ years. The level of self-esteem was evaluated by the Rosenberg Self-Esteem Scale RSES, anxiety was measured by the Sport Anxiety Scale SAS-2, and coping strategies to manage stress were assessed by the Athletic Coping Skills Inventory ACSI-28. The study used the correlational research design with Spearman correlation coefficient. Results: We found that coping strategies to manage stress have significant relationship with at least one anxiety construct of the ice hockey players, namely coping with adversity, coachability, concentration, goal setting and mental preparation, peaking under pressure and freedom from worry. We also found that coping strategies to manage stress have significant relationship with the selfesteem of ice hockey players, namely coping with adversity, concentration and freedom from worry. Conclusion: Our research showed that the level of coping strategies to manage stress varies according to the level of self-esteem and the level of the anxiety. It seems that reduced anxiety and increased self-esteem can lead to better stress management and optimal competition performance.
\end{abstract}

Keywords: mental skills, stress management, match, athletes, sport psychology

\section{Introduction}

Ice hockey is a team contact sport which puts high demands on physical, physiological, technical, tactical and mental skills of ice hockey players. There are many studies investigating physical profile of ice hockey players (Ransdell \& Murray, 2013; Roczniok et al., 2016), physiological correlates of skating performance (Farlinger, Kruisselbrink, \& Fowles, 2007; Gilenstam, Thorsen, \& Henriksson-Larsén, 2011), prevalence of injuries (Emery et al., 2017; Tuominen, Stuart, Aubry, Kannus, \& Parkkari, 2015), technical skills of ice hockey players (Janot, Beltz, \& Dalleck, 2015) or tactics in ice hockey (Hristov, 2017). But there are few studies exploring the mental skills of ice hockey players which may increase sports performance in important moments of the match.

\footnotetext{
* Address for correspondence: Adriana Kaplánová, Faculty of Physical Education and Sport, Comenius University in Bratislava, Nábrežie armádneho generála Ludvíka Svobodu 42e98/9, 814 69 Bratislava, Slovak Republic. E-mail: kaplanova8@uniba.sk
}

Sweating, increased heart rate, fidgeting, inattention and negative thoughts are typical symptoms of anxiety in sport. Hanton, Mellalieu, and Williams (2015) found that competitive sport has the potential for a high level of stress and anxiety. Anxiety is a typical response to a situation where an athlete's skills are being evaluated (Smith \& Smoll, 1990). According to Weinberg and Gould (2015) anxiety can manifest itself as a stable part of one's personality known as trait anxiety, or as a temporary, more malleable, situation-specific state anxiety. Anxiety is made up of worrying thoughts and apprehensions (cognitive component) and degree of physical activation (somatic component). The factors which can increase stress and anxiety are: physical demands, psychological demands, environmental demands or expectations and pressure to perform to a high standard (Reilly \& Williams, 2003).

There are coping strategies which may help athletes to manage stress in important moments of the match (Smith, Schutz, Smoll, \& Ptacek, 1995). Previous research showed that psychological skills of athletes 
change depending on requirements in sport (Bebetsos, 2015; Bebetsos \& Antoniou,2003; Young \& Knight, 2014), as well as depending on the level of athletes (Géczi, Bognár, Tóth, Sipos, \& Fügedi, 2008). The results of the ice hockey study showed that the more experienced ice hockey players had better control under stress and lower levels of anxiety than younger ice hockey players (Géczi et al., 2008). Therefore, increasing a well-founded need investigating the psychological skills of ice hockey players and prevent it from occurring maladaptive fatigue syndrome. Henschen (2000) gives a definition of maladaptive fatigue syndrome as being physical and mental fatigue caused by a combination of stressors from mental, physical and social sources. It is a multidimensional psychobiosocial state resulting in a withdrawal from a formerly enjoyable or motivating activity due to excessive fatigue, which is manifested anger, hostility, anxiety, confusion, depression, sadness, lack of vigour, apathy and mainly reduce performance in sport (Hanin, 2000).

The term self-esteem can be defined as overall emotional evaluation of one's worth or value and thus, reflect a person's sense of confidence (Breckler, Olson, $\&$ Wiggins, 2008). Self-esteem is an indication of an overall level of mental development of the individual, is a socially conditioned and serves as a level of self-determination (Berdibayeva, Nurdaulet, Murat, Zhanar, \& Gulmira, 2014). According to Orlick and Partington (1988) self-esteem is one of the significant mental skills necessary for success in ice hockey. Developing knowledge of sports psychology may help the coaches choose more appropriate training procedures and increase selfesteem of athletes (Kaplánová \& Gregor, 2018).

Frustration and disappointment is often a response of ice hockey players to an imbalance between development player's skills in training and results in a match. The results of research Pellizzari, Bertollo, and Robazza (2011) showed that best performance was achieved by athletes who set goals, prepared themselves for the competition and listened to their coaches' instructions. In the study of Géczi et al. (2008) adult ice hockey players achieved a higher score in subscale peaking under stress and freedom from worry than younger ice hockey players. It means that adult national team ice hockey players were more prepared to give excellent performances in stressful situations and worry less about the negative things that could happen to them in a match (Jooste, van Wyk, \& Steyn, 2013; Smith et al., 1995).

There is the need for psychological training of ice hockey players at an early age. Ice hockey players need to control their emotions in stressful situations, to be able to relax and compete enthusiastically (Chase, Magyar, \& Drake, 2005; Daroglou, 2011; Gould, Dieffenbach, \& Moffett, 2002; Kaplánová, 2018). Although there are studies investigating coping strategies to manage stress (Vidic, Martin, \& Oxhandler, 2017; Young \& Knight, 2014), as well as studies investigating anxiety of athletes in competition (Hashim, Shaharuddin, Hamidan, \& Grove, 2017; Ramis, Vilandrich, Sousa, \& Jannes, 2015) and a level of self-esteem of athletes (Mannarini, 2010; Vasconcelos-Raposo, Fernandes, Teixeira, \& Berterlii, 2012) to the best of our knowledge our study is first work which tries to explain how anxiety and self-esteem affect coping strategies to manage stress in hockey. Therefore, we have established two research questions: Is there a relationship between coping strategies to manage stress and anxiety of ice hockey players? Is there a relationship between coping strategies to manage stress and self-esteem of ice hockey players?

\section{Methods}

\section{Participants}

The study sample consisted of 40 male ice hockey players aged from 20 to 28 , with an age of $21.67 \pm 1.94$ years. The study sample was composed of students studying for a coach specializing in ice hockey at the Faculty of Physical Education and Sports, Comenius University in Bratislava. The sporting age of ice hockey players in our research was $15.38 \pm 2.15$ years. The research involved ice hockey players training on the ice 5 times a week for 3 hours.

\section{Rosenberg Self-Esteem Scale RSES}

The Rosenberg Self-Esteem Scale was selected to determine the level of self-esteem of ice hockey players. This scale is a widely used self-report instrument for evaluating individual self-esteem. It is composed of a 10-item scale that measures global self-worth by measuring positive and negative feelings about the self. All items are answered using a 4-point scale format ranging from 1 (strongly disagree) to 4 (strongly agree). Items are recorded that the high score corresponds to a high level of self-esteem and a low score of a low level of selfesteem. Scores range from 10 to 40, with higher scores indicating higher self-esteem (Blatný \& Osecká, 1994; Rosenberg, 1965).

\section{Sport Anxiety Scale SAS-2}

The level of anxiety of ice hockey players was measured by the Sport Anxiety Scale. This scale is a multidimensional measure of cognitive and somatic trait anxiety in sport performance settings. It is composed of a 15 -item scale and includes three factors: somatic anxiety, worry and concentration disruption. The somatic construct involved various indices of autonomic arousal centered 
in the stomach and muscles. The worry construct involved concerns about performing poorly and the resulting negative consequences and the concentration disruption construct involved difficulties in focusing on task-relevant cues. The response format for each item consists of a linear 4-point scale ranging from 1 (not at all) to 4 (very much). The score for each subscale is calculated as the mean of the scores of subscale items and varies from one to four, with a low score indicating a less intense form of that type of competitive anxiety and a high score indicating a high probability of exhibiting that type of anxiety (Smith, Smoll, Cumming, \& Grossbard, 2006).

\section{Athletic Coping Skills Inventory ACSI-28}

Coping strategies of ice hockey players were assessed by the Athletic Coping Skills Inventory. This inventory is a validated tool commonly used in discovering the level of coping skills among athletes. It is composed of 28 items and 7 sport specific sub-scales, which are used to reflect a multidimensional construct of psychological skills. Each statement in the inventory describes experiences of other athletes, which prompts the participant to indicate the frequency of similar experiences. The response format for each item consists of a linear 4-point scale ranging from 0 (almost never) to 3 (almost always). Scores range from a low of 0 to a high of 12 on each subscale, with higher scores indicating greater strengths on that subscale. The score for the total scale ranges from a low of 0 to a high of 84 , with higher scores signifying greater strength (Smith et al., 1995).
The study design was approved by the Ethics Committee of the Comenius University in Bratislava. Ice hockey players were informed about the goals and objectives of data collection and their use for research purposes. Participants signed written informed consent before the start of the study. Data were collected and administered by a sport psychologist (the author of the study).

\section{Statistical analysis}

Descriptive statistics were used to give an indication of mean scores on subscales of psychological skills, anxiety and self-esteem of ice hockey players. The study used the correlational research design in order to assess the relationships between the self-esteem, anxiety of ice hockey players and their coping strategies to manage stress. We used Spearman correlation coefficient, which is used in the non-parametric distribution of data. The significance level was set at .05 and .01 for all statistical tests. The data were analyzed using the SPSS statistical program (Version 23 for Windows; IBM, Armonk, NY, USA).

\section{Results}

The descriptive statistics included a range of both scales, minimum/maximum values and standard deviations which are presented in Table 1. Cronbach's alpha indices were calculated for both measures employed in the study to ensure the reliability of these inventories

Table 1

Descriptive statistics of ice hockey players

\begin{tabular}{|c|c|c|c|c|c|}
\hline & Range of the scale & Mean & $S D$ & Minimum & Maximum \\
\hline \multicolumn{6}{|l|}{ Sport Anxiety Scale SAS-2 } \\
\hline Somatic & $5-20$ & 8.55 & 2.36 & 5 & 14 \\
\hline Worry & $5-20$ & 9.95 & 3.67 & 5 & 18 \\
\hline Concentration disruption & $5-20$ & 7.68 & 2.46 & 5 & 13 \\
\hline Total score & $15-60$ & 26.18 & 7.16 & 16 & 44 \\
\hline \multicolumn{6}{|l|}{ Rosenberg Self-Esteem Scale RSES } \\
\hline Total score & $10-40$ & 32.3 & 3.88 & 22 & 38 \\
\hline \multicolumn{6}{|l|}{ Athletic Coping Skills Inventory ACSI-28 } \\
\hline Coping with adversity & $0-12$ & 6.10 & 1.92 & 3 & 10 \\
\hline Coachability & $0-12$ & 6.63 & 2.92 & 2 & 12 \\
\hline Concentration & $0-12$ & 6.70 & 1.98 & 3 & 11 \\
\hline Confidence and achievement motivation & $0-12$ & 7.65 & 1.56 & 5 & 12 \\
\hline Goal setting and mental preparation & $0-12$ & 6.20 & 2.64 & 1 & 10 \\
\hline Peaking under pressure & $0-12$ & 6.08 & 3.21 & 1 & 12 \\
\hline Freedom from worry & $0-12$ & 8.18 & 2.83 & 1 & 12 \\
\hline Total score & $0-84$ & 47.53 & 10.94 & 31 & 69 \\
\hline
\end{tabular}


for the particular data-set. Tests of the instruments' reliability showed acceptable values for Athletic Coping Skills Inventory $\alpha=.86$, for Sport Anxiety Scale $\alpha=.87$, as well as for Rosenberg Self-Esteem Scale $\alpha=.71$.

The results of correlation analysis between the selfesteem, anxiety of ice hockey players and their coping strategies to manage stress are presented in Table 2 . As seen in Table 2 there are significant relationships between the self-esteem, anxiety of ice hockey players and their coping strategies to manage stress namely coping with adversity, concentration and freedom from worry. A statistically significant correlation was also found between somatic and worry components of anxiety and coachability, as well as peaking under pressure. All correlations between investigated variables reached a low or moderate level of statistical significance. A low but statistically significant association was also found between the somatic component of anxiety and goal setting and mental preparation of ice hockey players. There was no significant association between confidence and achievement motivation and anxiety, as well as self-esteem of ice hockey players. Our results indicate that the level of coping strategies to manage stress varies according to the level of self-esteem and level of the anxiety of ice hockey players.

\section{Discussion}

At present, there has not been a single study either evaluating its relationship between anxiety or selfesteem and coping strategies to manage stress in sport. There were some studies carried out earlier by Young and Knight (2014) in risk sport or Vidic et al. (2017) in basketball but these studies were only focused on investigating the level of the coping strategies to manage stress or the differences in mental skills between experienced and less experienced athletes (Géczi et al., 2008). However, there has not been a study investigating other factors which may have relationships with coping strategies to manage stress. Our study is thus the first that has shown significant relationships between anxiety, self-esteem and coping strategies to manage stress in ice hockey.

One of the important factors of successful performance in competition is ability to remain calm in stressful situations (Géczi et al., 2008; Smith et al., 1995). Our research showed that ice hockey players with a high level of the self-esteem and low level of the anxiety have a good psychological resilience and know to quickly bounce back from mistakes or setbacks. Our research also showed that ice hockey players with a low level of somatic and worry construct of anxiety, are able to listen to their coach and accepts constructive criticism without taking it personally and becoming upset. Ice hockey players who do not have autonomic arousal centered in the stomach and muscles and do not worry about performing poorly, can lead a coach's instruction more easily than ice hockey players with a high level of somatic and worry construct of anxiety. We did not find a statistically significant correlation between construct concentration disruption of anxiety, self-esteem and subscale of coachability. It seems that the level of selfesteem, as well as the construct concentration disruption of anxiety of ice hockey players, does not have an influence on ability to lead to the coach's instructions.

Lack of concentration is one of the most frequent complaints athletes during the competition (Smith et al., 1995). We found that concentration is associated with self-esteem and anxiety level of ice hockey players. It seems that ice hockey players with a high level of

Table 2

Results of correlation analysis between the Athletic Coping Skills Inventory ACSI-28, Sport Anxiety Scale SAS-2 and Rosenberg Self-Esteem Scale RSES

\begin{tabular}{|c|c|c|c|c|}
\hline \multirow[b]{2}{*}{$\begin{array}{l}\text { Athletic Coping Skills Inventory } \\
\text { ACSI- } 28\end{array}$} & \multicolumn{3}{|c|}{ Sport Anxiety Scale SAS-2 } & \multirow{2}{*}{$\begin{array}{c}\text { Rosenberg Self- } \\
\text { Esteem Scale RSES } \\
\text { Total score }\end{array}$} \\
\hline & Somatic & Worry & $\begin{array}{l}\text { Concentration } \\
\text { disruption }\end{array}$ & \\
\hline Coping with adversity & $-.66^{* *}$ & $-.65^{* *}$ & $-.46^{* *}$ & $.47^{* *}$ \\
\hline Coachability & $-.62^{* *}$ & $-.45^{* *}$ & -.15 & .03 \\
\hline Concentration & $-.49^{* *}$ & $-.38^{*}$ & $-.37^{*}$ & $.52^{* *}$ \\
\hline Confidence and achievement motivation & -.23 & -.01 & -.17 & .12 \\
\hline Goal setting and mental preparation & $.32^{*}$ & .28 & .08 & -.13 \\
\hline Peaking under pressure & $-.37^{*}$ & $-.39 *$ & -.18 & .07 \\
\hline Freedom from worry & $-.86^{* *}$ & $-.63^{* *}$ & $-.42 * *$ & $.34^{*}$ \\
\hline
\end{tabular}

Note. Statistically significant correlations are in boldface. ${ }^{*} p<.05, * * p<.01$. 
self-esteem and low level of anxiety are able to focus on performing tasks, even when adverse or unexpected situations occur. Smith et al. (1995) reported that athletes who are confident and positively motivated consistently know to gives great sports performance during competition. We did not find a statistically significant correlation between the subscale of confidence and achievement motivation and self-esteem and anxiety of ice hockey players. It seems that the level of self-esteem, as well as somatic, worry, concentration disruption of anxiety of ice hockey players, does not have an influence on positive motivation and works hard to improve skills during training.

Goal setting and mental preparation are also in the context of a set of attributes that allow a person to become a better athlete and able to cope difficult training and difficult competitive situations (Omar-Fauzee et al., 2014; Smith et al., 1995). In our study we found that a high level of somatic construct of anxiety of ice hockey players, who have autonomic arousal centered in the stomach and muscles, can be more prepared for competition. We did not find a statistically significant correlation between the construct of worry, construct of concentration disruption of anxiety, self-esteem of ice hockey players and the subscale of goal setting and mental preparation. It seems that level of self-esteem and level of anxiety, except for somatic construct of anxiety, does not have an influence on mentally prepared ice hockey players for competitions.

Sometimes athletes are not able to give an excellent performance in stressful situations and their performance does not correspond to the results of training (Omar-Fauzee et al., 2014; Smith et al., 1995). In this case we found that ice hockey players with a low level of somatic and worry construct of anxiety have a good stress management and they are able to perform better. It seems that autonomic arousal centered in the stomach and muscles and worry about sports performing reduce performance of ice hockey players in important moments of a match. We did not find a statistically significant correlation between the construct concentration disruption of anxiety, self-esteem and subscale of peaking under pressure. It seems that level of self-esteem, as well as construct concentration disruption of anxiety of ice hockey players, does not have an influence on sports performance in important moments of a match.

Sometimes people are worried about what others are thinking about them. Especially, what others will think when they perform poorly (Jooste et al., 2013; Smith et al., 1995). Our research showed that ice hockey players with a high level of self-esteem and a low level of anxiety, do not have to worry. It seems that they are mentally strong enough, value their efforts and compete with enthusiasm compared ice hockey players with a low level of self-esteem, and high level of anxiety.

Our research showed that there is a relationship between self-esteem, anxiety of ice hockey players and their coping strategies to manage stress. We found that coping strategies to manage stress have significant relationship with at least one anxiety construct of the ice hockey players. We also found that coping strategies to manage stress are in relation to the self-esteem of ice hockey players. Although our study sample of adult hockey players considered as representative for the conditions of Slovakia. In the future, we recommend exploring a wider research sample and compare results with findings in other countries.

\section{Conclusion}

Our research showed that the level of coping strategies to manage stress varies according to the level of selfesteem and level of anxiety of ice hockey players. It seems that reducing anxiety and increasing self-esteem of ice hockey players can improve sports performance in important moments of a match. Our findings may help coaches and sport psychologists develop effective interventions to reduce anxiety and increase self-esteem of ice hockey players and improve performance of ice hockey players in important moments of the match.

\section{Conflict of interest}

There were no conflicts of interest.

\section{References}

Bebetsos, E. (2015). Psychological skills of elite archery athletes. Journal of Human Sport and Exercise, 10, 623-628.

Bebetsos, E., \& Antoniou, P. (2003). Psychological skills of Greek badminton athletes. Perceptual and Motor Skills, 97, 1289-1296.

Berdibayeva, S., Nurdaulet, I., Murat, M., Zhanar, Z., \& Gulmira, A. (2014). Research of the characteristics of self-esteem of modern Kazakh adolescents and older adolescents. Procedia - Social and Behavioral Sciences, 128, 458-462.

Blatný, M., \& Osecká, I. (1994). Rosenbergova škála sebehodnocení: struktura globálního vztahu k sobě [Rosenberg's scale of self-esteem: Structure of the global relation towards the self]. Československá psychologie, 38, 481-488.

Breckler, S. J, Olson, J. M., \& Wiggins, E. C. (2008). Social psychology alive. Toronto, Canada: Thomson Nelson.

Chase, M. A., Magyar, T. M., \& Drake, B. M. (2005). Fear of injury in gymnastics: Self-efficacy and psychological 
strategies to keep on tumbling. Journal of Sports of Sciences, 23, 465-475.

Daroglou, G. (2011). Coping skills and self-efficacy as predictors of gymnastic performance. Sport Studies and Sport Psychology, 14, 1-6.

Emery, C. A., Black, A. M., Kolstad, A., Martinez, G., Nettel-Aguirre, A., Engebretsen, L., ... Schneider, K. (2017). What strategies can be used to effectively reduce the risk of concussion in sport? A systematic review. British Journal of Sports Medicine, 51, 978-984.

Farlinger, C. M., Kruisselbrink, L. D., \& Fowles, J. R. (2007). Relationships to skating performance in competitive hockey players. Journal of Strength and Conditioning Research, 21, 915-922.

Géczi, G., Bognár, J., Tóth, L., Sipos, K., \& Fügedi, B. (2008). Anxiety and coping of Hungarian national ice hockey players. International Journal of Sports Science and Coaching, 3, 277-285.

Gilenstam, K. M., Thorsen, K., \& Henriksson-Larsén, K. B. (2011). Physiological correlates of skating performance in women's and men's ice hockey. Journal of Strength and Conditioning Research, 25, 2133-2142.

Gould, D., Dieffenbach, K., \& Moffett, A. (2002). Psychological characteristics and their development in Olympic champions. Journal of Applied Sport Psychology, 14, 172-204.

Hanin, Y. L. (2000). Emotions in sport. Champaign, IL: Human Kinetics.

Hanton, S., Mellalieu, S., \& Williams, J. M. (2015). Understanding and managing stress in sport. In J. M. Williams \& V. Krane (Eds.), Applied sport psychology: Personal growth to peak performance (pp. 207-239). New York, NY: McGraw-Hill.

Hashim, H. A., Shaharuddin, S. S., Hamidan, S., \& Grove, J. R. (2017). A multisample analysis of psychometric properties for the Malaysian adapted Sport Anxiety Scale-2 among youth athletes. Psychological Reports, 120, 141-157.

Henschen, K. (2000). Maladaptive fatigue syndrome and emotions in sport. In Y. L. Hanin (Ed.), Emotions in sport (pp. 231-242). Champaign, IL: Human Kinetics.

Hristov, R. (2017). Research and characteristics of the tactics in the ice hockey. Activities in Physical Education \& Sport, 7, 19-21.

Janot, J. M., Beltz, N. M., \& Dalleck, L. D. (2015). Multiple off-ice performance variables predict on-ice skating performance in male and female Division III ice hockey players. Journal of Sports Science \& Medicine, 14, 522-529.

Jooste, J., van Wyk, J. G. U., \& Steyn, B. J. M. (2013). The relationship between mental skills and level of cricket participation. African Journal for Physical Health Education, Recreation and Dance, 19, 254-265.

Kaplánová, A. (2018). Individual differences of sensitivity of tennis players to injustice situations from the perspective of the five-factor model of personality Big Five Theory. Acta Gymnica, 48, 21-26.

Kaplánová, A., \& Gregor, T. (2018). Sebahodnotenie tenistov a ich vztah k citlivosti voči nespravodlivosti [Self-esteem of tennis players in relation with sensitivity to injustice]. Telesná výchova a šport, 28(1), 10-14.

Mannarini, S. (2010). Assessing the Rosenberg self-esteem scale dimensionality and items functioning in relation to self-efficacy and attachment styles. TPM - Testing,
Psychometrics, Methodology in Applied Psychology, 17, 229-242.

Omar-Fauzee, M. S., Don, Y., Susterna, N., Saputra, Y. M., Hanif, S., Abdullah, N. M., \& Shahril, M. I. (2014). Examining the Indonesia and Malaysia student-athletes coping strategy in sports. European Scientific Journal, 2, 1857-1881.

Orlick, T., \& Partington, J. (1988). Mental links to excellence. Sport Psychologist, 2, 105-130.

Pellizzari, M., Bertollo, M., \& Robazza, C. (2011). Pre- and post-performance emotions in gymnastics competitions. Journal Sport Psychology, 42, 278-302.

Ramis, Y., Vilandrich, C., Sousa, C., \& Jannes, C. (2015). Exploring the factorial structure of the Sport Anxiety Scale-2: Invariance across language, gender, age and type of sport. Psicothema, 27, 174-181.

Ransdell, L. B., Murray, T. M., \& Gao, Y. (2013). Off-ice fitness of elite female ice hockey players by team success, age, and player position. Journal of Strength and Conditioning Research, 27, 875-884.

Reilly, T., \& Williams, A. M. (Eds.). (2003). Science and soccer. London, United Kingdom: Routledge.

Roczniok, R., Stanula, A., Maszczyk, A., Mostowik, A., Kowalczyk, M., Fidos-Czuba, O., \& Zając, A. (2016). Physiological, physical and on-ice performance criteria for selection of elite ice hockey teams. Biology of Sport, 33, 43-48.

Rosenberg, M. (1965). Society and the adolescent self-image. Princeton, NJ: Princeton University Press.

Smith, R. E., Schutz, R. W., Smoll, F. L., \& Ptacek, J. (1995). Development and validation of a multidimensional measure of sport-specific psychological skills: The Athletic Coping Skills Inventory-28. Journal of Sport and Exercise Psychology, 17, 379-398.

Smith, R. E., \& Smoll, F. L. (1990). Sport performance anxiety. In H. Leitenberg (Ed.), Handbook of social and evaluation anxiety (pp. 417-454). New York, NY: Plenum Press.

Smith, R. E., Smoll, F. L., Cumming, S. P., \& Grossbard, J. R. (2006). Measurement of multidimensional sport performance anxiety in children and adults: The Sport Anxiety Scale-2. Journal of Sport \& Exercise Psychology, 28, 479-501.

Tuominen, M., Stuart, M. J., Aubry, M., Kannus, P., \& Parkkari, J. (2015). Injuries in men's international ice hockey: A 7-year study of the International Ice Hockey Federation Adult World Championship Tournaments and Olympic Winter Games. British Journal of Sports Medicine, 49, 30-36.

Vasconcelos-Raposo, J., Fernandes, H. M., Teixeira, C. M., $\&$ Berterlii, R. (2012). Factorial validity and invariance of the Rosenberg Self-Esteem Scale among Portuguese youngsters. Social Indicators Research, 105, 483-498.

Vidic, Z., Martin, M. S., \& Oxhandler, R. (2017). Mindfulness intervention with a U.S. women's NCAA Division I basketball team: Impact on stress, athletic coping skills and perceptions of intervention. Sport Psychologist, 31, 147-159.

Weinberg, R. S., \& Gould, D. (2015). Foundations of sport and exercise psychology. Champaign, IL: Human Kinetics.

Young, P. R., \& Knight, E. L. (2014). Use of psychological skills by risk sport athletes. Journal of Human Performance in Extreme Environments, 11, 1-9. 